\title{
Innovative Revolution of Library Information Work under the Background of Digital Information
}

\author{
Xiuhua Ma \\ Library, Jilin Agricultural University, Changchun, 130118 \\ 3259024068@qq.com
}

Keywords: Digital information; Library information; Innovative revolution

\begin{abstract}
With the advent of the Internet age, the development of digital information technology puts forward higher requirements to the innovative revolution of the library information work. The industry of information work plays an increasingly important role in the domestic information market. Library information work is the mainstream of information service industry. The traditional model of library information management cannot meet the public's spiritual needs in the background of knowledge, difficult to stand still in today's complicated work information system. Therefore, it is urgently needed for library information work to innovate the mechanism, for improving the advantages of library information work in the development of science and technology.
\end{abstract}

\section{Introduction}

At present, under the tide of information revolution, information data resources, energy resources and materials are listed equally as the three major resources in the world. The library as the concentrated area of the main information resources of the society, shoulders the important responsibility for spreading knowledge and information in the process of human development. Library information work can be said to the heart of the library. In order to keep up with the development of digital information network, library information work should assess the situation and innovate timely to adapt to the development of the Internet age.

\section{The Necessity of the Revolution of Library Information Work under the Background of Digital Information}

In the context of networked digital information, the dependence on Internet gets bigger and bigger for people. Library information work, carried by Internet, can provide people with services of remote search, multi-use and multi-channel access to information. Digital information is changing the mode of library information management, breaking the limitations of services, which provides the original driving force for innovation of library information work.

Firstly, in the background of digital information, distribution of library literature information is unbalanced, and users will have a variety of obstacles in the search of information. All the time, the users of the library information are always using the service modes of literature retrieval or the transmission to obtain the information resources. However, due to the differences of countries and regions, the application levels of network technology and the ways access to information are different, so that digital gap occurred. Many people still have no way to obtain resources through the network, because they do not have the same conditions to enjoy the opportunities in the use of network, In addition, many of the library information websites have a low coverage, not familiar to people, leading to that the ways access to information are limited.

Secondly, the uncertainty of the value of network information resources requires the innovation of library information work. Although the digital information resources are very rich in the Internet age, the disorder, complex and open information bring some interference to users on the contrary, because they do not have enough time to classify and integrate information that have be queried, some information appears repeated, Acquiring accurate information looks like finding a needle in a haystack. After all, the network is a free and open system without management, where massive 
information blow, that will bring users polluted information, such as the hacker attacks, profiteering content and chaotic spam, which are calling for the reform of library information work.

Thirdly, the complexity of the digital information compels the library information work to change, to recapture the information market. The development of science and technology provides convenience for people to obtain the latest information, so that people gradually change the way of information exchange, creating information environment, shortening the time of information exchange, improving the efficiency of learning, and eliminating a lot of communication barriers, but many scientific workers face with new issues of information exchange in the new situation. the users of library information stay away in front of network technology, which puts forward higher requirements on reform of the library information. It should continue to excavate the potential for purpose of occupying one position in the information market .

Fourthly, for many users, the awareness of the using network is relatively weak, they do not want to take the time to learn new technologies, which requests library information work to get reformed constantly and simplifies the process to consolidate their own number of users. In fact, even in the context of digital network information, there are still many traditional information users acquiring information using the traditional method, and even some users, especially older ones, holding a hostile attitude to the Internet, prefer to retrieve by their own hand, do not recognize the network search, do not learn network skills, negatively keep the concept that surfing Internet is entertainment. This creates a number of barriers to their own access to information since majority of the latest library information messages are first appearing on the website. Even though some people access resources from the Internet, but feel blind and not be able to handle the huge retrieval results, leading to that the requirements of acquiring library information cannot be met often. In addition, some families or regions cannot touch the network because of the constraints of the economic capacity; this part also is a potential market for the reform of the library and information work. Currently, many users reflect that the transmission speed of network is a little bit slow, and that the price of some information is on the relatively high, not suitable for public demand.

\section{Countermeasure of Innovative Revolution of Library Literature Information Work}

To Improve the Information Literacy Level of Staffs in Library Literature Information. Under the background of digital information, the modes of library books borrowing and books collection of the traditional library have gradually become the center of information-based data collection. Library can provide a large number of users with library information access to services, which makes demands on the staff. The requirements for staff are not high under traditional mode, and they are just responsible for some mechanical work, but now, the staff not only need to master the management knowledge, but also should know well the network technology and establish the completely new recognition on digital date information, at the same time, improve information literacy continually by oneself to set up consciousness of digital network. First of all, the library information staff should adhere to learn network knowledge continually. Through re-education, they can master the basic knowledge of computer operation, understand the approach to obtain information, familiar with the ways of retrieving information, re-shape own knowledge construction and the ability of innovative work. Secondly, the staff should continue to learn to meet the diverse knowledge needs of library information users, and constantly looking for answers from the question to promote themselves. Thirdly, library information workers should strengthen their awareness of the network digitalization and have their own cognitive attitudes and ideas in various fields such as society, science and technology, so that they can have their own judgment on the information of library information, grasp the mainstream of the times in time, Constantly deepen and develop new information, and update the resource database, to provide users with better service.

The Innovation and Reconstruction of Library and Information Management. The development information of network digital information, the exchange and access of information are no longer setting books as the carrier, while the database has gradually embarked on the cusp. According to the investigation on network date information from the University of California in America, they found that $1 \times 1081$ bytes of information probably be excavated in the world annually, 
in the process, the network-based information occupy the main block. Network information resources have occupied the majority of information resources. So far, all the domestic printing industry publishers have begun to reduce the volume of printed products, and establish a library literature database of digital information, as well as provide users with retrieval services including the most advanced information. So re-building the digital resource information of library information industry using new technology method is imminent. At present, the library information resources, services, communication and user needs continue to be integrated and updated, to offer conditions for users to change the approach of acquiring information. The related departments of library information should be constantly updated and tap the potential information needs of users, to develop library information and information mechanisms to meet user requirements. Besides, the library should also change the traditional work mode, expanding the scope of library and information work, for example, online Search, automatic search library, and so on, to provide a convenient way for information access.

The Mining and Integration of Information Resources of Library Literature. Library electronic reading room has gradually established, so that a lot of resources can be obtained through the network. The diversified information resources basically cover library collections, but due to the digital resources stemming from different directions, so it is too much troubles for users to find useful information in such a wide range of databases and efficiency of finding useful information is relatively low. Normally, the process needs to go through repeated comparison, wasting users' time; above all, it is difficult to achieve the target of resource sharing effectively. Therefore, the most urgent problem is digging and integrating the digital resources effectively and perfect the intelligent service system, to improve the efficiency of retrieving useful information for users. The departments of library information can improve cross-database retrieval methods for the heterogeneous databases. For general users, it is possible to get incomplete information when they retrieve one database, so some information needs to depend on cross-database retrieval. However, different databases inevitably display the different screens because of the various encoding scheme, where the users need to adapt to different retrieval methods and rules, but the retrieval operation is very cumbersome, therefore, library information staff should integrate the different database resources to achieve convenient search across the library. First of all, the staffs can design the search interfaces for every one of databases, to achieve retrieval sharing of information between the multiple network databases, so that users avoid wasting time derived from using the different interfaces. Second, improve cross-library automatic retrieval, library information staff can integrate the digital information on a certain kind of topic or a class professional content from different databases, so that users can search information automatically using cross-library retrieval. Besides, management personnel can also set the system security permissions to improve the security of information resources. Finally, the departments of library information can cooperate with community intelligence agencies, after all, the community's intelligence agencies have professional intelligence personnel who grasp the dynamic information accurately, this can help departments of library information to improve the insight of information, benefit to the development of information.

The Important Meaning and Significance of Innovative Revolution in Library Information Work. The innovative revolution of library information work not only is the objective requirement of social and scientific development, but also the inherent requirement of own sustainable development. It can promote the transformation of the traditional mode of the library, expand the business of the library and reflect the important value of library information work. First of all, innovation of library information work can improve the systems and mechanisms of relevant business, serving the users as the center of library information work to set meeting its information search as the main task. The mission of library' is to provide users with high-quality services, setting that connecting the needs of users throughout the library information work in all aspects as the final the goal. Secondly, although the libraries have to provide the site and place for the library and information service, innovating the mode of the library information can transfer to build up the resource database and the information inquiry system. The traditional physical space and the present 
virtual space should cooperate with each other to realize the value. The Staffs in the work of innovation should prompt the value of the physical space of the library improved. Thirdly, it is helpful to promote the updating and perfection of the informationized library, to a certain extent, reduce the pressure of library information staff, besides, the integration and sharing of different database resources can improve the utilization rate of information resources and provide convenience for users.

\section{Conclusions}

Library information work bears the functions of recording, compiling, organizing, retrieving functions from the beginning. With the development and progress of the times, the departments of library information need to reform constantly, grasp the advantages of information access to meet the users' requirements firmly, and improve the information literacy level of library information staffs continually, meanwhile, mine and integrate the latest information resources, to provide users with the most convenient retrieval services.

\section{References}

[1] Ma Jiangbao. Research on the actuality of resource co-construction of China's libraries alliance. Journal of Shandong Library Science, 2013 (3): 65-70.

[2] Guo Bailing. Collection of public opinion, gathering of wisdom, making full use of the positive role of the network public opinion. Theoretical Perspective, 2012 (3): 69-70.

[3] Chi Lianxiang. Analysis on the legal and policy environment of library industry development in China. Library World, 2012 (6): 56-59

[4] Gong Guowei, Wang Mei.Video text system and its application in library and information service.Library and Information Technology,1984(1): 41

[5] Yuan Hui. Network requirements of the library information needs of the user characteristics and personnel training. Modern Information, 2002 (7): 101-102.

[6] Sheng Gongping, Huang Hongchao. The category and mode of information services under network circumstance. Modern Information, 2002 (6): 134-136.

[7] Xu Yinchi. The future of library information industry. Hefei. China University of Science and Technology Press, 1998.

[8] Tan Yushan, Liu Shizhang. Organization of network information resources. Internet World, 1999, 3.

[9] Liu Zhengheng, Zhang Jiuzhen. Investigation on the new characteristics of library construction under the network environment. Journal of Peking University, 1997, 105-109.

[10]Liu Xiuhua. The revolution and development strategy of library under network circumstance. Journal of China University of Mining and Technology (Social Science Edition), 2002 (3).

[11]Wang Chongde. The impact of network on the theory and method of library information science. Journal of Library Science in China, 1998 (6).

[12] Shi Bojun. Effective utilization of networked information resources on the research and analysis of library information work. Journal of Henan Library Science, 2011, 3 (6): 27-28 